\title{
Magallanes y la lucha contra las enfermedades infecciosas de los niños. Muerte, pasión y vida (Parte II)
}

\author{
Matías Vieira
}

\begin{abstract}
Hospital Clínico de Magallanes Dr. Lautaro Navarro Avaria. Servicio de Salud Magallanes Unidad de Patrimonio Cultural.

Recibido: 3 de octubre de 2013
\end{abstract}

Correspondencia a: Matías Vieira Guevara matvi46@gmail.com.

\section{Struggle against infectious diseases in children in the Magallanes Region. Death, passion and life. (Part II)}

The first part of this work was published in the previous issue of this magazine. In order to finalize with the historical review of infectious diseases which have been determining factors on regional infant mortality, we analyze firstly the case of religious missions and its impact on the rapid extinction of Patagonian Indians. Secondly, we review the health situation of Punta Arenas during the first half of the 20th century, switching from a high mortality rate from infectious or contagious diseases, to a remarkable improvement in this issue, coming to bear the best health indicators in the country.

Key words: Patagonia, Magallanes Region, history, childhood infectious diseases, Salesian missions, Anglican missions, Patagonian Indians, tuberculosis, history of Punta Arenas.

Palabras clave: Patagonia, Región de Magallanes, historia, enfermedades infecciosas infantiles, misiones salesianas, aborígenes australes, tuberculosis, historia de Punta Arenas.

\section{Un genocidio bien intencionado}

$\mathrm{E}$ 1 por qué de la rápida extinción de las razas aborígenes en la Patagonia tiene miradas con distintos cristales. Cualquier apasionamiento en estas consideraciones las hará pecar de sesgadas, y quizás aún faltan algunos años de análisis histórico para poner las cosas en su justa medida. Es cierto, eso sí, que de muchos factores que pudieron ser determinantes en esta tragedia, hay tres que son de indudable peso: la oleada de buscadores de oro, la oleada de las grandes empresas ganaderas, y la oleada de misioneros. Mucho se ha escrito y dicho sobre las dos primeras, de modo que haré sobre ellas un repaso somero, para detenerme un poco más en la tercera, que es más atingente a esta revisión ${ }^{1}$.

\section{Los mineros}

Hasta el descubrimiento del oro en la isla de Tierra del Fuego (1878) la relación de los colonos con los indígenas era más bien pacífica, y éstos realizaban trueques de pieles y plumas por tabaco, licor y víveres. El "vil metal" atrajo la llegada de pirquineros con ganas de trabajar y hacer fortuna, pero además llegó una caterva de aventureros y facinerosos. Dice Mateo Martinic: La diversión brutal con alguna india de las que merodeaban por los asientos... significó que las relaciones entre mineros y los onas fueran en extremo violentas. Muchas veces aquellos que disponian de armas maltrataron a los indigenas, arrebatándoles sus mujeres y ocasionándoles heridos o muertos, respondiendo los naturales con asaltos a los campamentos $^{6}$. Este intercambio carnal, en este caso forzado, habría sido el inicio de las enfermedades de transmisión sexual, hasta entonces desconocidas por los aborígenes. No había autoridad, y el rumano Julius Popper estableció un gobierno aparte en sus minas de oro, llegó a acuñar monedas, introdujo sellos postales, y contaba con ejército propio. Cito a Gusinde: La fiebre del oro también atrajo a aventureros de los bajos fondos de Europa. Cuando éstos se encontraban con indigenas, las consecuencias para los mismos eran funestas. El indio tenía fama de ser un enemigo peligroso, en cuyo territorio no se había adentrado hasta entonces ningún europeo. Cuando se acercaba a tiro de fusil lo mataban sin miramientos. Siempre luchaba en la defensiva con desventaja. No faltaban las peores violencias contra las indias ${ }^{2}$. Hay muchas y más atroces descripciones de éste y varios autores, las que omito por lo ya expresado más arriba.

\section{Los ganaderos}

Cuando aún se mantenía este estado de cosas con la minería del oro, hace su irrupción la ganadería, con la concesión de millones de hectáreas a las grandes sociedades por parte del estado. Vino el cercado de las propiedades, el maltrato a los indígenas, el robo de ganado por parte de los mismos, en suma, la violencia desatada ${ }^{1,4}$. Cito a Borrero, autor de "La Patagonia Trágica": ... el primer trabajo a realizar era la destrucción y exterminio de los indios, como para formar una "chacra" se extirpan $y$ destruyen previamente árboles, raices y malas hierbas ${ }^{5}$. Tampoco abundaré en este tema.

\section{Los misioneros}

Ya hacia 1851 se establecían las primeras misiones anglicanas en las comarcas aledañas al Canal Beagle, 


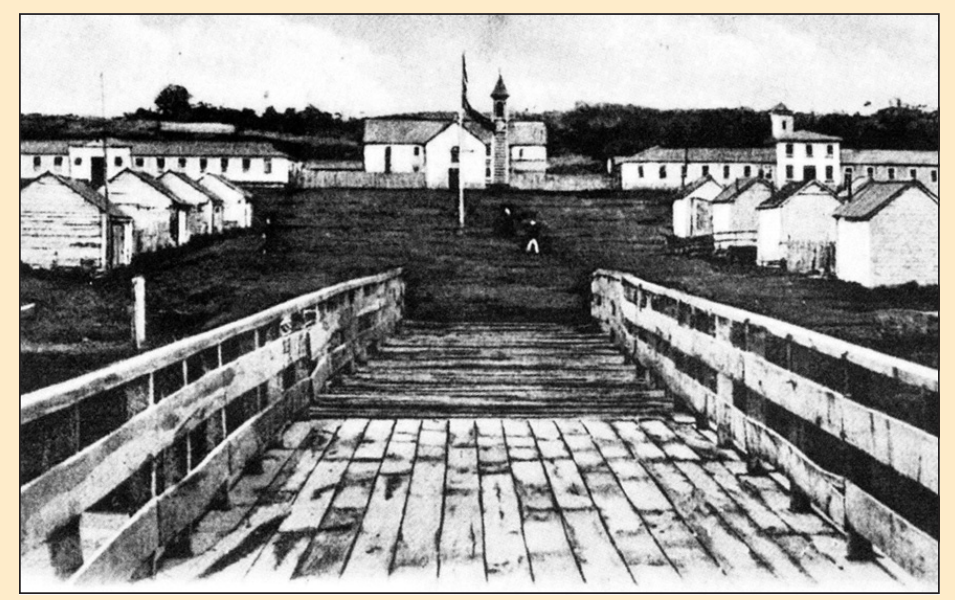

Figura 1. Misión salesiana en Isla Dawson hacia 1895.

las que dirigían sus esfuerzos evangelizadores principalmente a la etnia yámana. Como consecuencia no deseada, hacia 1882 este pueblo estaba severamente diezmado por la tuberculosis. ${ }^{1}$ En 1884 un brote de sarampión redujo a la mitad a la población indígena allí residente. Mateo Martinic cita al respecto al misionero y estanciero Lucas Bridges: (...) en pocos dias murieron en tal cantidad, que no había tiempo de cavar sus fosas, y los muertos de los distritos eran simplemente sacados de sus chozas o cuando los otros ocupantes tenian suficientes fuerzas, arrastrados hasta los arbustos más cercanos. Más adelante comenta Bridges: Es, sin embargo, extraordinario que esta enfermedad, propia de los niños, tan contagiosa en los centros civilizados y que rara vez es fatal, lo fuera para más de la mitad de la población de un distrito... ${ }^{1}$.

Cumpliendo el sueño de Don Bosco de evangelizar y civilizar a los habitantes originarios de la Patagonia, arribaron a nuestras costas los Salesianos y las Hijas de María Auxiliadora. Su líder natural, por así decirlo, fue el notable sacerdote y obispo Giuseppe Fagnano. Arribado inicialmente a la Tierra del Fuego argentina, acompañando a las primeras incursiones militares colonizadoras en estos territorios, rápidamente se dio cuenta del desmedro en que se encontraban los indígenas, tanto por su propia naturaleza como por los abusos que se cometían en su contra ${ }^{1,3}$.

No escapó a Fagnano la constatación del efecto deletéreo que provocaba sobre los aborígenes el contacto con los "gérmenes" que transmitía el hombre blanco. Sobre un grupo que había llevado a establecerse en Punta Arenas escribe: ... vi con mucho sentimiento que las dos familias iban sufriendo en su salud, tanto que a pesar de los cuidados del Sr. Dr. Lautaro Navarro y de las Hijas de María Auxiliadora perecieron del pulmón todos los individuos. Entonces, pensé en ensayar en la Isla Dawson... ${ }^{4}$.

Aparte de las misiones itinerantes, los salesianos establecieron fundamentalmente dos reducciones: una de ellas fue San Rafael (1889-1911), para lo cual consiguieron por parte del gobierno de Balmaceda la cesión por veinte años de la enorme Isla Dawson, de unos $1.330 \mathrm{~km}^{2}$; y la otra misión, fundada más tarde, fue La Candelaria en Río Grande, Argentina 7 .

Estos espacios misioneros reduccionales tenían como propósito la cristianización y educación de los indígenas, en que aprenderían oficios que autoabastecieran la misión y que cambiarían por completo su cultura, sentido religioso y vida cotidiana ${ }^{7}$. Para 1895 la misión San Rafael en Dawson contaba con un camino desde el muelle, iglesia,

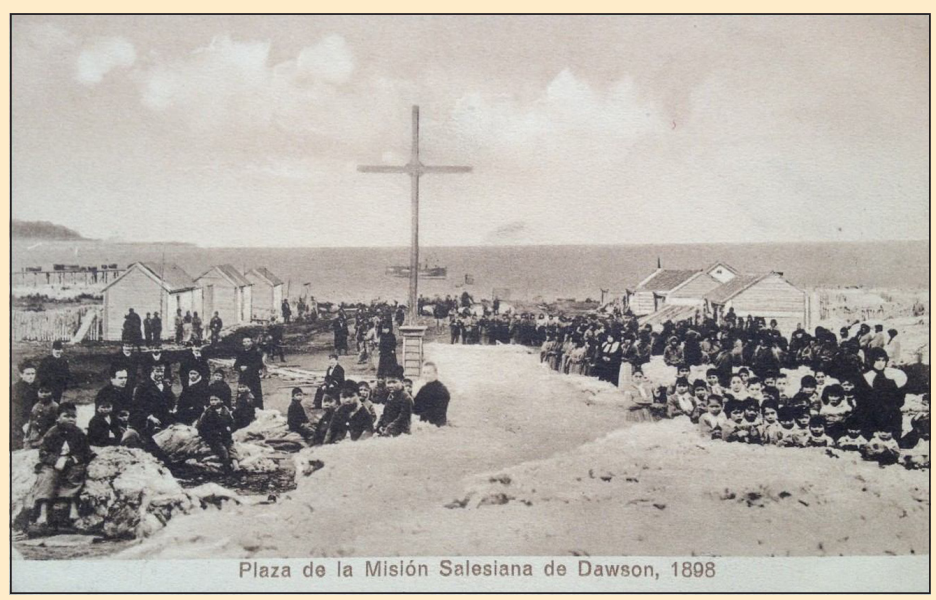

Figura 2. Misión salesiana en Isla Dawson, 1898.

CUADRO RESUMEN DEI, NUMERO DE INDIOS QUE IIABIA Y DE LOS MUERTOS EN CIADA ANO

Año Muertos

1889: Los indios en San Rafael ascendieron at

1890: Los indios en San Rafacel ascendieron

1891: Los indios en San Rafael atscendieron it

1892: Los indios en San Rafacel ascendieron it (en su mayoria alacalufes)

1893: Los indios en San Rafael ascendieron it

1894: Los indios en San Rafael ascendieron (en su mayoría alacalufes)

1895: Ascendieron a (aumentan los onas)

1896: Aumentaron de 270 a (mayoría onas)

1897: Aumentaron de 350 a (mayoría onas)

1898: Aumentaron de 400 a

1899: Descendieron a (parte se fugaron)

1900: Descendieron :

1901: Descendieron

1902: Descendieron it

1903: Descendieron a

1904: Descendieron a

1905: Descendieron a

1906: Descendieron a

1907: Descendieron :

1908: Descendieron a

1909: Descendieron a

1910: Descendieron a

1911: Hasta septiembre descendieron at

Total de los muertos:

\begin{tabular}{rc}
45 & 1 \\
97 & 3 \\
13() & 5 \\
$160)$ & 8 \\
& \\
180 & 10 \\
195 & 18 \\
& \\
215 & 30 \\
30() & 115 \\
400 & 145 \\
550 & 110 \\
350 & 95 \\
205 & 80 \\
180 & $(6)$ \\
160 & 30 \\
150 & 35 \\
130 & 24 \\
105 & 35 \\
& \\
82 & 18 \\
64 & 14 \\
53 & 11 \\
48 & 7 \\
39 & 5 \\
& \\
36 & 3 \\
\hline & $8(62(219)$ \\
$5:$ &
\end{tabular}

Figura 3. La misión en la Isla Dawson (1889-1911). Fuente: Aliaga, referencia № 4.

casa de los salesianos, casa de las monjas, escuela, talleres, hospital, panadería, matadero y casas de las familias indígenas ${ }^{3,4}$ (Figuras 1 y 2). También contaba con un cementerio propio, que lamentablemente hacia el final de las misiones terminó siendo el lugar más poblado. ${ }^{7} \mathrm{Se}$ trajo un aserradero completo desde Europa y se instaló en Dawson, ante el asombro de los indígenas, que veían cómo entraban troncos y salían tablas ${ }^{4}$. 
¿Cómo y por qué llegaban los indígenas a las misiones? Algunos ganaderos dejaron de pagar una libra esterlina por cabeza de indio, y en cambio les pagaban esa misma cantidad a los misioneros para que se hicieran cargo ${ }^{4}$. Algunos llegaban en forma voluntaria y, los más, prácticamente arreados por las autoridades. Los gobiernos se identificaban con las grandes empresas ganaderas, que de ellas dependía el progreso y desarrollo de la zona, y los indígenas constituían un estorbo. No cesaba la violencia, y a lo largo de 1894 se sucedieron una serie de enfrentamientos sangrientos entre blancos e indios, con muertes por ambos bandos, y "El Magallanes" escribía: ... es realmente vergonzoso que en el Estrecho de Magallanes, frecuentado diariamente por vapores se desarrollen escenas de sangre como las que relatamos. En último caso, hágase una campaña de exterminio contra los indios adultos y déjese los niños a cargo de los salesianos ya que ellos creen poder civilizarlos, pero que no veamos repetirse escenas como la anterior que avergüenzan a un país como Chile que ocupa un rango entre las naciones civilizadas $^{4}$. No sería la primera ni última vez que se promoverían crímenes en nombre de la civilización.

La prosperidad de este verdadero poblado en Dawson hizo reaccionar a los elementos anticlericales, instigados por el diario “El Magallanes”, el que acusaba a los salesianos de estar enriqueciéndose a costa de territorios estatales y con la mano de obra indígena. Monseñor Fagnano fue el blanco de las críticas ${ }^{4}$. El almirante Manuel Señoret, a la sazón Gobernador del Magallanes, quiso implantar una suerte de misión laica, vale decir, civilización sin evangelización. Para ello planteaba llevar a los indígenas directamente, en calidad de empleados, a donde hubiese trabajo, sin importar el hecho de que muchos de ellos ni siquiera tenían el concepto de lo que era trabajar para un patrón. Es así como, muchas veces los indígenas tomados cautivos en sus tierras, en lugar de ser llevados a Dawson, primero eran encerrados en corrales en Punta Arenas, donde eran rematados y llevados a trabajar a estancias y aserraderos ${ }^{4,5}$. Sobre uno de estos episodios escribía el diario conservador "El Chileno": ... en medio de las escenas más desgarradoras que he visto o espero ver en mi vida. (...) Al comprender que les arrebataban a sus hijos, los indios salieron de su habitual serenidad $y$ dócil placidez y dando gritos horribles con ademanes desesperados, trataron de defender a sus criaturas. Cada niño arrebatado originaba una escena. La madre se echaba sobre su hijo defendiéndolo con su cuerpo, mientras el padre con la expresión de todas las furias en los ojos, dando aullidos que daban pavor, se lanzaban sobre los que le robaban su niño, atacándolos con las manos, los dientes y las uñas... ${ }^{4}$. Como consecuencia de estas prácticas escribe Martín Gusinde: ... se impuso la "moda" de que las familias más pudientes acogieran a un niño selk'nam (...) Aparte del cambio en la vestimenta, alimentación, habitación y forma de vida, su acrecentada predisposición para todo tipo de enfermedades tuvo consecuencias nefastas. En especial la tos convulsa y el sarampión han hecho estragos, y han causado la muerte de muchos; otro tanto ha hecho la tuberculosis pulmonar. Todas estas familias bien intencionadas, sin excepción, tuvieron las mismas experiencias infortunadas con estos niños. ${ }^{2}$ Todos murieron antes de crecer.

Conocido es el genocidio de la conquista española, la cual se ejerció más con la espada que con la cruz. A los pueblos patagónicos sin embargo, al decir de Gonzalo Vial, los mataron nuestras manos republicanas, no el cruel conquistador legendario. Tuvo parcialmente la culpa una intención buena, aunque homicida: la de civilizarlos $^{5}$.

En 1895 la misión contaba con 215 indígenas, la mayoría onas, y al final del año habían fallecido treinta. ${ }^{5}$ En 1901 se presentaba en Dawson el P. Pablo Albera, Visitador Extraordinario de las Obras Salesianas de América. Su secretario anota: Esta desventurada raza parece que está destinada a perecer, tanto por la guerra que se les hace para destruirla, como por enfermedades importadas por extranjeros, contribuyendo también mucho la pérdida de sangre que degenera en tisis ${ }^{4}$. Después de la epidemia de escarlatina de 1905, la misión comienza a agonizar. Les atacó a los pobres indígenas a casi todos simultáneamente. Una fiebre elevadísima parecía devorarlos. Se les aconsejaba no se movieran de la cama y que tomaran en abundancia bebidas calientes y sudoriferas que les proporcionaban amenazándoles que si no obedecian moririan inevitablemente. Hablar al viento. Apenas quedaban solos salian de la cama, recostándose sobre el suelo, bebiendo agua fría cuanto más podian. Tenderse sobre la hierba fresca era para ellos el mayor alivio. La muerte hizo estragos y contados fueron los atacados que no sucumbieron. La misión se redujo casi a la nada ${ }^{4}$. Entre 1905 y 1906 fueron además víctimas de una epidemia de viruela que diezmó a casi toda la población tehuelche, y en la misión quedaban solamente 82 fueguinos $^{5}$ (Figura 3). Con razón había advertido Robustiano Vera ya en su libro de 1897: Se nota que el indio fueguino, una vez que se le arranca de sus costumbres i se le civiliza, le entra tisis galopante i fallece. No se sabe a qué atribuir este resultado.

El 23 de septiembre de 1911, después de 22 años, siete meses y 20 días, se embarcaron con destino a Punta Arenas 10 salesianos, 4 hijas de María Auxiliadora y 25 indígenas que serían enviados a la Misión de La Candelaria en Argentina ${ }^{1,3,4}$. La viruela, tuberculosis, escarlatina y otras enfermedades habían acabado con el resto (Figura 4).

\section{Punta Arenas: del pozo negro al alcantarillado}

Quiero terminar con estas pinceladas, hasta aquí trágicas, refiriéndome al progreso sanitario que fue 
determinante sobre las enfermedades infecciosas de los niños, desde comienzos hasta los dos tercios del siglo $\mathrm{XX}$. He puesto a Punta Arenas como un mero indicador, por ser el centro más poblado de la región. Su desarrollo en el tema que nos interesa es extrapolable, con lógicos desfases temporales, al resto del territorio, incluyendo áreas rurales y urbanas (Figura 5).

Justo en el cambio de siglo, entre 1898 y 1901 se creaba el Servicio de Vacuna, el Consejo Departamental de Higiene y la Junta de Sanidad Marítima, que marcaban el interés de las autoridades en la prevención de enfermedades infecciosas.

A comienzos de siglo XX la situación seguía bastante precaria, pese a haberse inaugurado en 1906 el Hospital de Caridad (Figura 6). Este nosocomio, sin embargo, pese a su moderna planta física, su relativamente actualizado equipamiento y contar con competentes profesionales, entregaba y recibía caridad. La comunidad, especialmente las grandes empresas, lo mantenían con erogaciones y fondos obtenidos con beneficios. Contaba con pabellón de niños, el cual debió ser a todas luces insuficiente.

Según los antecedentes aportados por el censo de 1908 dirigido por el Dr. Lautaro Navarro a comienzos del siglo XX, hubo brote epidémico de viruela en 1901, 1905 y 1906; tos convulsiva en 1901 y 1907; influenza en 1900 y 1906; la tuberculosis pasó a ser endémica y de altísima incidencia; se describen casos de tifoidea y neumonía croupal o fibrinosa, que sin duda corresponde a la ominosa difteria. Todas estas enfermedades infecto-contagiosas fueron determinantes en la altísima mortalidad infantil que presentaba la región. De hecho, el $52 \%$ de los fallecidos eran menores de 6 años ${ }^{1}$.

Sin embargo, curiosa e inexplicablemente, Magallanes ostentaba en 1903 menor mortalidad infantil que el promedio nacional: 334 contra $371 \%$. ¿Sería verdad, entonces, que los defensores de los fríos y vientos huracanados tenían razón? En todo caso seguían siendo cifras atrozmente elevadas.

El servicio de agua potable y alcantarillado, cuyas obras se habían iniciado varios años antes, se inauguraba ipor fin! en 1908. Con todas sus limitaciones, fue obviamente un gran adelanto sanitario, recibido con gran regocijo por los habitantes de la ciudad.

Gran parte de la sanación (y también la mortalidad) infantil se hacía en los domicilios, ya sea recurriendo a la medicina popular y sus hierbas, quiebres de empacho, y contras para el mal de ojo, o con visitas domiciliarias de facultativos. Relata Nicolás Mihovilovic en sus memorias hermosamente escritas en el libro Desde Lejos Para Siempre, refiriéndose al eslovaco Mateo Bencur (Figura 7), quien ejerció en Punta Arenas entre 1907 y 1923: ... todos los niños de esa casa en una u otra forma le debíamos la vida al doctor Mateo Bencur. Él nos había mejorado de la escarlatina y de la terrible tos convulsiva. Con su grueso impermeable, su ancho sombrero, su bastón, su

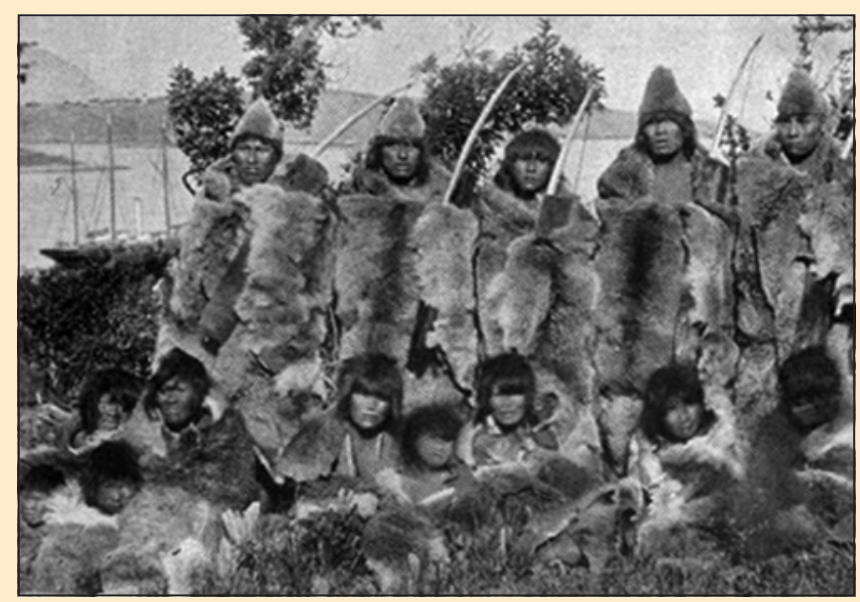

Figura 4. Aborígenes Selknam de Tierra del Fuego.

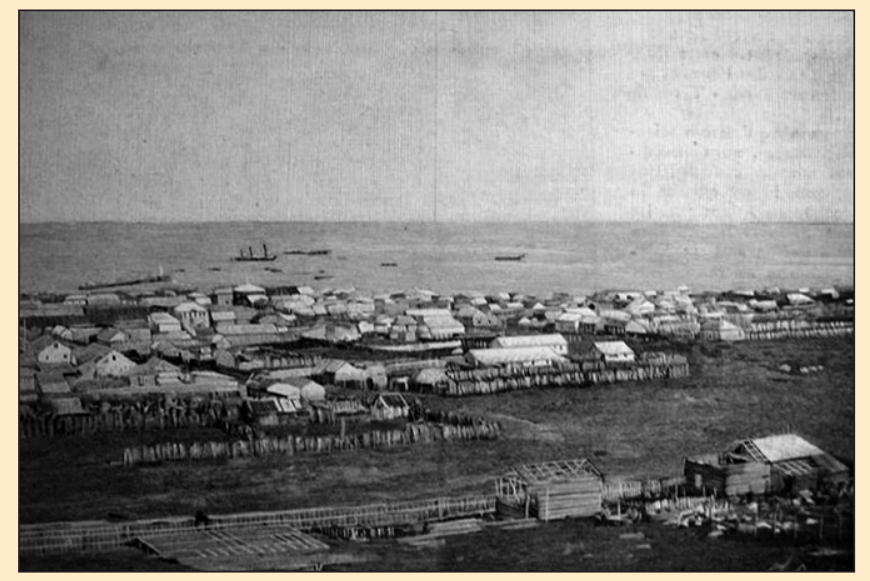

Figura 5. Colonia de Punta Arenas hacia 1850.

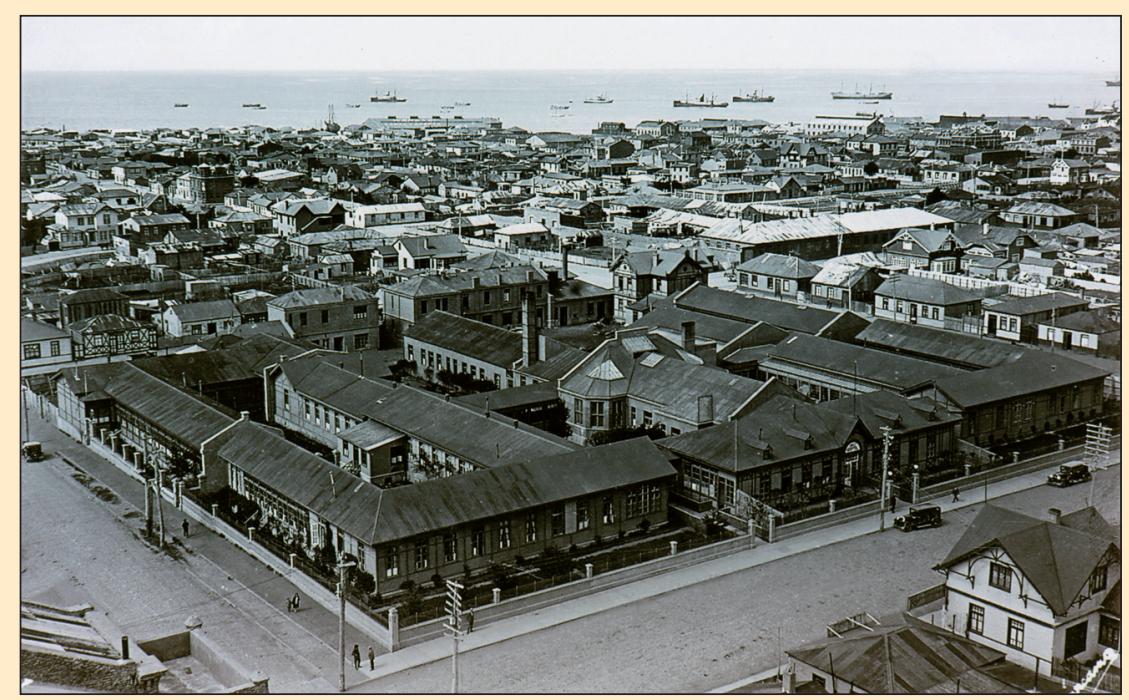

Figura 6. Hospital de Caridad. 


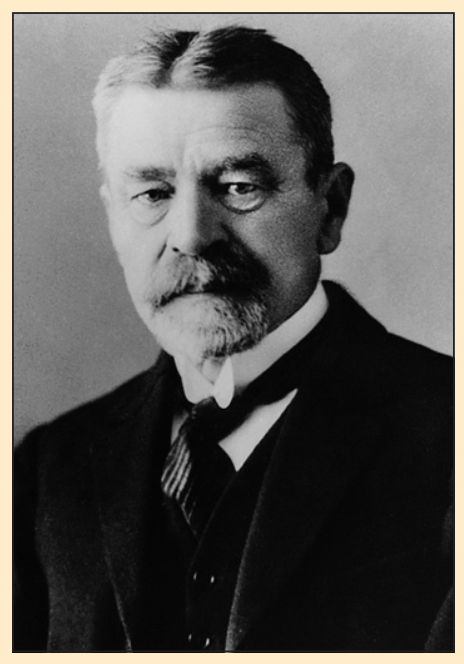

Figura 7. Dr. Mateo Bencur.

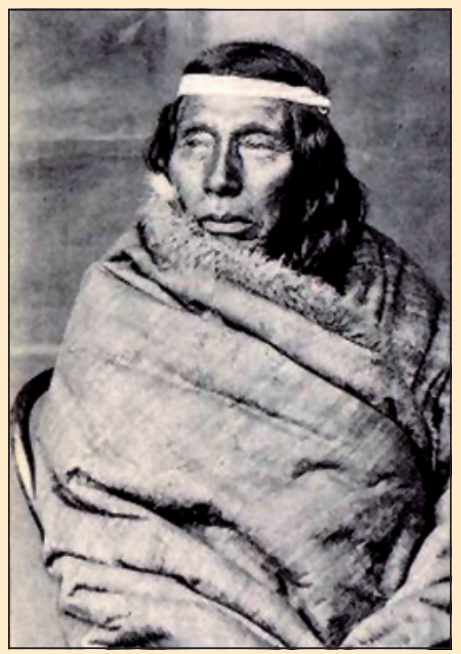

Figura 8. Cacique $\mathrm{Mu}$ lato.

barbita en punta, y, calzando botas, arrollada al cuello una ancha bufanda de lana, habia repechado en crudas noches de invierno las empinadas calles llenas de charcos helados o de barro pegajoso; contra el viento, la lluvia y la nieve... a cualquier hora, cualquier dia, en cualquier momento. $Y$ de nuestra casa habia ido a muchas, muchas otras, próximas o lejanas, pobres o ricas. Y muchas veces, en vez de extender la receta, sacaba de los hondos bolsillos de su impermeable, la pastilla o el frasquito de remedio que entregaba a la dueña de casa "porque aquello le estaba sobrando y no había por qué gastar plata y hacer rico al boticario"s.

Impresiona la pequeña nota publicada en "El Magallanes" (sin dársele demasiada importancia, a juzgar por la falta de abundancia sobre el tema) del 3 de diciembre de 1913: "A consecuencia de la enorme mortalidad infantil, se ha agotado la existencia en plaza de ataúdes para niños. En los últimos días ha habido que pagar por dicho articulo precios exorbitantes".

Cito nuevamente a Mihovilovic, a propósito del funeral de una niña. Decía su padre croata: “... aqui mueren demasiados niños. Casi no hay familias que no tengan dos o tres hijos allí, en el cementerio más bello y más terrible que he visto en mi vida... Más de la mitad de las tumbas son de niños..." El doctor Bencur miró a mi padre con serenidad: "No me lo diga a mi que cada día firmo certificados de defunción. Pero, afortunadamente, cada año van siendo menos. (...) Este clima es propicio para el raquitismo y la tuberculosis y, además, casi nadie sabe alimentarse... ni prevenirse. Hay familias enteras contagiadas por la tisis, condenadas a morir en pocos años". (...) De mis compañeros de curso cinco murieron ese año agotados por la tuberculosis. En el vecindario los velorios de los "angelitos" eran fiesta de cada noche... ${ }^{8}$ Este testimonio personal tiene más fuerza y dramatismo que las estadísticas.

Tal vez la gran paradoja es que esta tragedia se daba durante la primera época de oro de Punta Arenas, en cuanto al auge del emprendimiento y la creación de las grandes fortunas.

Todas estas enfermedades infecto-contagiosas iban también haciendo mella sobre la población rural indígena, que sucumbía irremediablemente al no tener un sistema inmunológico activado para enfrentar estas patologías por completo desconocidas antes del contacto con el hombre blanco. Resulta emblemático el caso del célebre Cacique Mulato (Figura 8), quien era conocido por su afabilidad y bonhomía, ganándose el cariño y respeto de los habitantes de Punta Arenas, quienes lo recibían gustosamente en sus visitas a la ciudad. Instalaba sus tolderíos, como buen nómade que era, entre Río Gallegos y el norte de Punta Arenas. Tan adaptado estaba a las costumbres del hombre blanco, que optó a concesión de tierras, haciéndose estanciero. Sintiéndose perjudicado por algunas medidas administrativas, viajó a Santiago, siendo amablemente recibido por el Presidente da la República. Hasta aquí, todo parecía ir bien. Pero el caso fue que en el viaje su nuera contrajo la viruela, y al regreso murió ella, Mulato y toda su familia. La enfermedad se extendió entre sus congéneres, y marcó la culminación de la extinción de la raza tehuelche en la Patagonia chilena ${ }^{1}$.

Cito nuevamente a Martinic: La preocupación alcanzó un grado máximo una vez que se hicieron públicos los resultados de las primeras investigaciones médico-sanitarias realizadas en 1918 en el alumnado de las escuelas fiscales. Así el doctor Abraham Dodds revelaría que en algunos cursos el ciento por ciento de los alumnos padecía de tuberculosis, raquitismo y/o debilidad general. Un año después, el médico Daniel Acuña declaraba al diario La Unión que Punta Arenas ocupaba el primer lugar en el país en cuanto a raquitismo infantil y tuberculosis ${ }^{1}$.

Hacia 1926 el apoyo sanitario seguía ejercido en gran 
parte por la generosidad de personas e instituciones de buena voluntad. Un ejemplo palmario venía siendo la Liga de Damas Católicas, las que apoyaban a la Gota de Leche, una suerte de consultorio para madres e hijos ${ }^{1,10}$. Aquí se repartían alimentos, ropa y medicinas, se educaba y se efectuaban atenciones médicas. Se destacaba la Dra. Elena Ancic de Barrios, primera en Magallanes que se dedicó a la atención de niños. En una de sus reuniones El profesor señor Werner Gromsch dictó una conferencia sobre tuberculosis, con proyecciones luminosas. Se premiaba a la madre del niño mejor criado y a la casa mejor tenida (...) para estímulo a las madres para el mejor cuidado de sus hijos y a las esposas para la mejor higienización de sus hogares ${ }^{10}$.

En 1934 la Asociación Médica de Magallanes convocaba a una asamblea pública para tratar el tema de la tuberculosis, en que se informó, según el diario El Magallanes, que la ciudad está completamente desarmada para defenderse contra este terrible enemigo, y han pasado los años en la indiferencia de los poderes llamados a tomar enérgicas medidas, y que también las salas del Hospital se encontraban siempre ocupadas por un $80 \%$ de tuberculosos ${ }^{1}$. Si bien, como decíamos, la mortalidad infantil en 1903, pese a sus cifras elevadísimas era menor al promedio nacional, se habían llegado a igualar hasta tomar Magallanes una no muy honrosa delantera: de este modo en 1936 era de 260 por mil nacidos vivos, contra 232 en el resto del país.

El raquitismo y la tuberculosis siguieron campeando durante muchos años en Magallanes. Hacia la década de 1940 la situación comienza a cambiar, como se verá. Cuando en el resto del país en 1942 había una mortalidad infantil de 195 por cada mil niños nacidos vivos, en Magallanes era "sólo" 119. Si no fuera por la tuberculosis, las cifras podrían haber sido mejores, ya que, por esta enfermedad, Magallanes aún tenía la mortalidad más alta del país. En 1940 había 5.000 tuberculosos en una provincia de casi 49.000 habitantes, y en el examen médico escolar se comprobaba un 10,4\% de tuberculosos ${ }^{9}$. En 1942 se fusionaron todos los organismos creados con antelación para la atención materno-infantil en un solo servicio, la Dirección General de Protección a la Infancia y la Adolescencia (Protinfancia). En 1944 el Ministro de Salubridad Dr. Sótero del Río declaraba: Los servicios de la Madre y el Niño recibirán un vigoroso impulso: se realizará una activa campaña para combatir la tuberculosis, que alcanza caracteres agudos en la región austral ${ }^{9}$. Quizás fueron los primeros intentos del gobierno central de participar activamente en la solución de los problemas sanitarios de las provincias, lo que se refrendaba con la resolución del señor Ministro de que La Jefatura Sanitaria Provincial de Punta Arenas ha procedido a modificar la forma de trabajo del personal de su dependencia, encuadrándose dentro del moderno concepto de Unidad Sanitaria con atención preferente a los sectores suburbanos... ${ }^{9}$. Parecía ser ipor fin! el germen de esa magna obra del Estado, que fue la creación del Servicio Nacional de Salud, por cuanto estas Unidades Sanitarias obedecerían a una misma normativa en las políticas de salud.

Se hablaba también, por esa época, de regular el funcionamiento de los mataderos, y el Jefe Sanitario Provincial Dr. Juan Damianovic, manifestaba que al mejorar el agua potable, ... la ciudad de Punta Arenas podría ser considerada como una de las más higiénicas del pais 9 . Este servicio llegaba a la mayoría de las casas, pero se consideraba insuficientes los tres filtros de arena con que se potabilizaba. Se aseguraba que ... un filtro de arena (...) en condiciones técnicas ideales, proporciona un agua que pierde el 99\% de las bacterias, pero en Punta Arenas la insuficiente filtración (...) hace variar totalmente dicho coeficiente. Asimismo (...) no se clora, de tal manera que es susceptible de convertirse en agente transmisor de enfermedades ${ }^{9}$. Constituían igualmente, por cierto, notables avances el aumento de la red de "desagües" y el Laboratorio Químico Bromatológico Municipal, que analizaba los productos lácteos y embutidos que llegaban de Argentina en viajes prolongados y sin la refrigeración adecuada ${ }^{9}$. Hitos importantes, que irían incidiendo favorablemente en el control de las enfermedades infecciosas.

Había, sin embargo, un déficit habitacional importante que atentaba contra todo esfuerzo de mejorar la salubridad. ... es aún más doloroso imponerse de que una buena parte de los obreros magallánicos se ven obligados a habitar ranchos miserables, en los que se apretujan con naturales y propios sentimientos de repugnancia. (...) La tuberculosis, que es un problema pavoroso en Punta Arenas, se debe, en gran parte, a la escasez de viviendas. Se dan casos de cuatro familias que habitan un rancho de dos cuartos, con la consiguiente promiscuidad y contagio ${ }^{9}$. En cuanto a los afiliados a la Caja de Seguro Obligatorio: ... dadas las condiciones climatéricas (sic) de la región, es indispensable procurar a los asegurados afectados del pulmón cuidados especiales. Sin embargo, como la Caja carece en Magallanes de un sanatorio, se suple esta falta enviando a aquéllos que necesitan reposo preventivo a casas particulares que cobran por la pensión menos que los hospitales ${ }^{9}$. Muy ingenioso y tal vez un ingreso extra para el hogar, pero obviamente son de prever las consecuencias de insertar en el seno de una familia a un esparcidor de bacilos.

Con motivo del cambio desde el Hospital Regional al nuevo Hospital Clínico de Magallanes, en funcionamiento desde 2010, encontramos entre los desperdicios de las bodegas, y a punto de ser enviado a los incineradores, el libro de partos del antiguo Hospital de Beneficencia (ex Hospital de Caridad) (Figura 9). Éste comprende entre 1943 y 1949, y en relación al tema que nos interesa, constatamos que la reacción de Kahn en la maternidad se implementó en 1944. Es así que pudimos observar que, de las madres de los 434 nacidos vivos en dicho hospital 


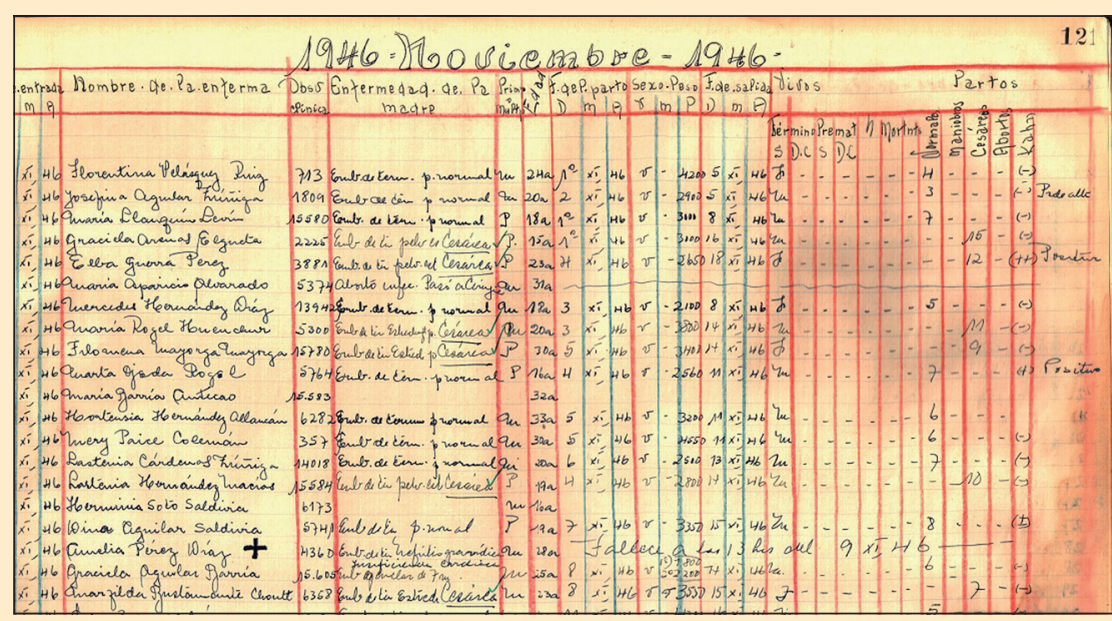

Figura 9. Libro de Partos del Hospital de Beneficencia.

durante ese año, a $85 \%$ se les practicó la reacción de Kahn. De éstas, 7,3 \% resultó positiva. Es decir, siete de cada 100 niños nacidos en el hospital estaban con una altísima probabilidad de ser portadores de sífilis congénita, sin considerar a los nacidos en domicilio o antes de 1944, que ni siquiera se diagnosticaron.

La sociedad tomaba conciencia, se hacía difusión radial y por la prensa escrita, charlas, proyección de películas, afiches, folletos. Eran notables las colonias escolares en la localidad de Agua Fresca, en que se inculcaba a los niños hábitos de higiene y conocimientos sanitarios ${ }^{9}$.

En tan nobilísima campaña aunaron sus esfuerzos los profesionales de la salud, las autoridades públicas y municipales; el magisterio, la prensa y entidades benéficas como la Cruz Roja, la Gota de Leche de las Damas Católicas, la Junta de Auxilio Escolar, la Liga Antituberculosa, y otras varias instituciones societarias. ${ }^{1}$

Todas estas instituciones, las acertadas políticas nacionales, la construcción de un nuevo hospital, esfuerzo mancomunado de unos y otros, hicieron cambiar la situación en forma radical, en forma lenta pero sostenida. En 1951 se daba por erradicado el raquitismo infantil, y en 1952 la mortalidad infantil había descendido a 66,1 en contraposición a 129,2 por mil nacidos vivos en el país.

Estos progresos coincidieron con la decidida intervención estatal, cuando desde mediados del siglo veinte comienza la segunda época de oro de Magallanes con el descubrimiento y desarrollo de la minería del petróleo. Esta vez sí se dio la lógica, en contraste con lo sucedido a comienzos de siglo.

Hasta hace no más de tres décadas Magallanes seguía ostentando los mejores indicadores sanitarios generales y de salud infantil en particular. No podemos aquí detallar los factores que determinaron esta asombrosa evolución. No cabe duda, en todo caso, que el esqueleto que sostenía este ahora vigoroso cuerpo fue la creación del Servicio Nacional de Salud, con sus políticas, normas, y red de establecimientos asistenciales. También, de fundamental importancia, la profesionalización de la enfermería y de la matronería, la preparación de los paramédicos, la llegada de pediatras y equipamientos adecuados, todo en un tránsito de mejoría constante y sostenida.

Hemos así transcurrido desde la pediatría artesanal domiciliaria hasta la tecnología hospitalaria avanzada, del pozo séptico al alcantarillado, de la tragedia a la alegría.

\section{Resumen}

La primera parte de este trabajo fue publicada en el número anterior de esta revista. Para finalizar con la revisión histórica de las enfermedades infecciosas que han sido determinantes sobre la mortalidad infantil regional, analizamos en primer lugar el caso de las misiones religiosas y su incidencia sobre la rápida extinción de los aborígenes australes. En segundo lugar revisamos la situación sanitaria de Punta Arenas durante la primera mitad del siglo XX, en que se pasó de una alta mortalidad por enfermedades infectocontagiosas, hasta la notable mejoría en este tema, llegando a ostentar los mejores indicadores sanitarios del país.

\section{Referencia bibliográficas}

1.- Martinic M. El adelanto sanitario (1894-1952). En: La medicina en magallanes. Noticias y consideraciones para su historia. Ed. La Prensa Austral, 2ª Ed. 2010.

2.- Gusinde M. Los indios de la Tierra del Fuego. Centro de Etnología Americana de Buenos Aires, Ed. 1982.

3.- Martinic M. Centenario del cierre de la misión de Dawson. Reflexiones sobre un esfuerzo admirable e infructuoso. Magallania (Chile) 2011; 39 (2): 97-103.

4.- $\quad$ Aliaga F. La Misión en la Isla Dawson (1889-1911). Anales de la Facultad de Teología, Universidad Católica de Chile 1981. Vol XXXII (Cuaderno 2).

5.- Orellana M. La misión salesiana en Isla Dawson: intento por evitar la extinción fueguina (1887-1919). Revismar 2007; $\mathrm{N}^{\circ} 2$.

6.- Martinic M. Panorama de la colonización en Tierra del Fuego entre 1881-1900. Anales del Instituto de la Patagonia. Serie Ciencias Humanas 1973; 4: 5-69.

7.- Nicoletti M. El modelo reduccional salesiano en Tierra del Fuego: educar a los "infieles". Revista TEFROS 2008; Vol. 6 (2).

8.- Mihovilovic N. Desde lejos para siempre. Ediciones Dalmacia, 5a Edición, Punta Arenas 2002.

9.- Revista En Viaje, Febrero 1944.

10.- Revista Menéndez Behety, Enero, Mayo y Junio 1926. 